\title{
Complexidade, conhecimento e educação: a emergência de um novo paradigma epistemológico no contexto contemporâneo
}

\author{
Complexity, knowledge and education: the emergence of a new \\ epistemological paradigm in contemporary context
}

Sidinei Pithan da Silva*

Universidade Regional do Noroeste do Estado do Rio Grande do Sul

Resumo O presente estudo tematiza a emergência de um novo paradigma epistemológico no cenário contemporâneo, o qual sinaliza para a problemática da complexidade implicada em toda dinâmica do conhecimento humano. A abordagem metodológica orienta-se por uma perspectiva hermenêutica e dialética, a qual busca privilegiar a leitura crítica das obras de Edgar Morin, situando-as numa leitura de conjunto e procurando extrair delas relações entre concepções epistemológicas, éticas e políticas. $\mathrm{O}$ resultado desta leitura, quando tematizada no âmbito escolar, consiste em compreender o novo desafio da escola no trato com o conhecimento. Para além de ensinar conhecimentos, a escola precisa ensinar uma nova relação com o conhecimento. Esta pressupõe uma leitura mediata e complexa da realidade, re-elaborando o significado da ciência e do conhecimento no contexto societário.

PalaVras-CHAVE: Complexidade; Conhecimento; Ciência; Educação.

\begin{abstract}
This study addresses the emergence of a new epistemological paradigm in the contemporary scenery, which points to the problem of complexity involved in the whole human knowledge dynamic. The methodological approach is guided by a hermeneutic and dialectical perspective, which intends to privilege the critical reading from Edgar Morin books, placing them in a set of reading and trying to extract the relation between epistemological, ethical and political concepts. The result of this reading, when thematized in the school place, is to understand the school's new challenge in dealing with knowledge. Besides teaching knowledge, the school needs to teach a new relation with knowledge. This presupposes a mediate and complex understanding of reality, reworking the science and knowledge meaning in the corporate context.
\end{abstract}

KEYWORDS: Complexity; Knowledge; Science; Education. 


\section{Introdução}

Este estudo constitui o esforço de compreender e apresentar as principais dimensões do "paradigma epistemológico da complexidade" no contexto teórico e educacional contemporâneo tematizados nos escritos de Edgar Morin. A escolha de investigar as obras deste autor se faz mediada pela preocupação de buscar explicitar a forma como lida com o contexto da crise da racionalidade moderna ou mesmo de crise do pensamento moderno. Sabemos, atualmente, que muitas são as produções em filosofia e ciências humanas que evidenciam esta crise (MARQUES, 1993; MARCONDES, 2002; NOVAES, 2006; JAPIASSU, 2012). Sob este prelúdio, cumpre evidenciar, de forma específica, como elas tocam no âmago da questão educacional, permitindo-nos problematizar o pensamento herdado. Não se trata aqui de criticar as ideias de Edgar Morin no sentido de buscar mostrar suas fragilidades e incoerências, mas, fundamentalmente, interpretar o movimento conceitual efetuado por ele para pensar nos vínculos entre ciência, educação e sociedade. Compromisso que se faz pautado por uma perspectiva hermenêutica, tal como a sugerida por Gadamer (1997), a qual exige um trato conceitual e interpretativo acerca das obras do autor, evidenciando, pela via da compreensão, as ideias nucleares ou mesmo os conceitos centrais do autor que permitem pensar o significado e a emergência da noção de paradigma da complexidade na educação. Para tanto, o estudo estabelece as seguintes perguntas de pesquisa: Qual a relação entre ciência, educação e sociedade no pensamento de Edgar Morin? Como pensar o conhecimento implicado no processo de educação escolar? Qual a perspectiva assumida por Edgar Morin em relação ao problema do conhecimento? Há possibilidades de pensar uma nova forma de se relacionar com o conhecimento a partir do paradigma da complexidade? Que desafios estão implicados aos educadores e à escola neste contexto?

Para tratar de tais questões, o presente estudo descreve, num primeiro momento, os vínculos e nexos estabelecidos entre educação, ciência e sociedade no contexto da modernidade em escritos de Edgar Morin. Busca-se, sobretudo, compreender a proximidade teórica das questões discutidas por Morin com as problemáticas levantadas por Heidegger e pelos teóricos da Escola de Frankfurt. Num segundo momento, o texto aponta para a possibilidade de repensar as relações educativas e o papel do conhecimento no cotidiano escolar. Tomando como pressuposto os princípios do paradigma da complexidade, são discutidas algumas questões relacionadas aos sentidos, caminhos e finalidades da educação escolar; o que possibilita, em última instância, situar as contribuições conceituais emergentes no campo paradigmático/epistemológico da complexidade, as quais reorientam a organização e desenvolvimento de uma nova relação com o conhecimento no cotidiano escolar/educacional.

\section{Educação, ciência e sociedade}

A questão que se coloca a toda e qualquer tentativa de resposta aos desafios da problemática educacional contemporânea refere-se, basicamente, às formas de racionalidade que devem orientar o processo constitutivo/educativo/formativo do Humano. As perspectivas provenientes do pensamento de Edgar Morin nos permitem entender que uma compreensão da educação contemporânea, e de suas possibilidades 
de mudança paradigmática, não pode estar desvinculada de uma reflexão acerca da relevância da racionalidade científica no contexto social. Trata-se, outrossim, de refletir e analisar a própria noção de ciência e conhecimento e sua crise que se tornou hegemônica no pensamento Ocidental e que configura a dinâmica do pensamento educacional.

Para Morin (2001a, p. 15) "há três séculos, o conhecimento científico não faz mais do que provar suas virtudes de verificação e descoberta em relação a todos os outros modos de conhecimento". O conhecimento científico tornou-se "o conhecimento vivo que conduz a grande aventura da descoberta do universo, da vida, do homem". As conquistas da ciência, argumenta ele, possibilitaram um fabuloso progresso ao nosso saber, possibilitando, por exemplo, "medir, pesar, analisar o sol, avaliar o número de partículas que constituem o nosso universo e decifrar a linguagem genética que informa e programa toda a organização viva”. Somente através deste conhecimento, que permite domínios nas esferas mais microscópicas e macroscópicas, tornou-se possível ao homem moderno efetuar "progressos técnicos inéditos, tais como a domesticação da energia nuclear e os princípios da engenharia genética”. No entanto, salienta Morin, concomitantemente com esta dimensão "fabulosa, elucidativa e triunfante da ciência", que permite realizar descobertas importantes e "satisfazer as necessidades sociais" e, assim, desabrochar a civilização, existe uma dimensão que causa, cada vez mais, também "problemas graves" (2001a, p. 15).

Com efeito, a ciência, na modernidade, possibilitou a expansão da "técnica", criando verdadeiras condições de emergência de um panorama para as relações humanas em escala mundial, criando novas formas de superar antigas dependências e heteronomias características de períodos históricos anteriores. No entanto, a ciência adquire, na modernidade, um papel altamente significativo na constituição, não apenas de novas técnicas, e de novas possibilidades de relação do homem com a natureza, e mesmo de tentar "fugir da natureza" (ARENDT, 2001), mas, fundamentalmente, na constituição dos "saberes fundamentadores", "reguladores" e "legitimadores" da vida social, ética e política. Por outro lado, não pode se ocultar o fato de que "o contexto social influenciado pela ciência" acaba também por "influenciar a própria ciência", fornecendo o "lugar", a "importância", "as possibilidades" e os seus limites no mundo humano. Para Morin

a relação ciência-sociedade é muito complexa porque a ciência, que partiu da periferia da sociedade, graças a alguns espíritos independentes, tornou-se uma instituição através das sociedades científicas, as academias. Hoje ela habita o coração da sociedade. Ao difundir a sua influência sobre a sociedade, sofre ela própria a determinação tecnoburocrática da organização industrial do trabalho. (MORIN, 2003a, p. 165).

A ciência, desta forma, não escapa às pressões sociais, sofrendo certa determinação tecnoburocrática, que embora lhe conceda uma determinada autonomia, acaba também por circunscrever seus limites e possibilidades de ação.

Logo, compreende-se que, no pensamento de Morin, a crítica do conhecimento moderno, ou mesmo da ciência moderna, é, em parte, a crítica à própria forma 
de constituição da sociedade moderna (PENA-VEGA \& ALMEIDA, 1999). Tornase possível identificar o vínculo deste aspecto do pensamento de Morin com a preocupação levantada no início do século XX por Heidegger (2012, p. 20) acerca da técnica moderna e, logo em seguida, na tematização feita pela Escola de Frankfurt acerca da modernidade (ADORNO \& HORKHEIMER, 2006). Valendo-se de Lefort (2006), podemos pensar no que separa Heidegger de Adorno ou de Horkheimer. Estes últimos, segundo ele, "inauguram o processo de acusação de um novo tipo de dominação que arruína os fundamentos da cultura e busca sua origem no racionalismo das luzes. Heidegger, sem utilizar a palavra crise, designa um momento crucial em que transparece a fragilidade da civilização" (LEFORT, 2006, p. 43).

Também se pode pensar, grosso modo, que a filosofia no século XX levanta o problema da técnica e da racionalidade de uma forma inédita, questionando a noção que se tornara constitutiva da modernidade, a qual vinculava a ideia de progresso social a partir da ideia de razão. Nesta nova forma de crítica, inaugurada no século XX, os próprios poderes do homem em relação à natureza e a si mesmo entram em questão. Logo, pensar e problematizar a própria noção de razão herdada tornara-se a forma de pensar a dominação após o cenário esboçado por Heidegger e pela Escola de Frankfurt. A máxima de Adorno e Horkheimer, esboçada na Dialética do Esclarecimento (2006), a qual afirma que a crítica da razão é a melhor crítica que a razão pode prestar, pode ser compreendida neste contexto. Esta parece parte da herança intelectual que ecoa sobre os ombros de Morin quando analisa as relações entre ciência, sociedade e educação.

$\mathrm{Na}$ leitura de Morin, a perspectiva cega e unidirecional de desenvolvimento tecnocientífico, associada a uma ciência parcelar, fragmentadora, contribuiu para a construção de ideários educacionais e sociais que desconsideraram a complexidade social, identitária, ética e política do Humano. Esta noção linear e positivista acerca do progresso relegou para um segundo plano a dinâmica auto-eco-organizacional contida no seio dos organismos e ecossistemas vivos, contribuindo para o surgimento e desenvolvimento de processos de dominação e exploração, onde acreditava estar contribuindo para a emancipação e libertação. Sob este aspecto, Morin interpreta que a crise contemporânea, configurada como crise da racionalidade moderna, é decorrente de uma noção cega da crença no progresso, de uma "fé na missão providencial da tecnociência" em alimentar a certeza do progresso e de um tipo particular de desenvolvimento que esperava grandes realizações (MORIN, 2002a, p. 88). Para Morin, o mito do desenvolvimento determinou a crença de que era preciso sacrificar tudo por ele. Isso permitiu, segundo ele, justificar impiedosas ditaduras, sejam as do modelo "socialista" (partido único) ou as do modelo pró-ocidental (ditadura militar). As crueldades das revoluções do desenvolvimento acabaram ainda por agravar as tragédias dos subdesenvolvidos (2003a, p. 83).

O problema de fundo, atacado por Morin, nesta crítica do pensamento moderno, refere-se à hegemonia daquilo que ficou conhecido como paradigma da racionalidade instrumental. Este paradigma, enquanto princípio ou mesmo núcleo obscuro que orienta os discursos teóricos (MORIN, 2001a, p. 45), parece ter predominado no âmbito de constituição da modernidade, operando pela lógica do cálculo, da simplifi- 
cação e da formalização. Ele conduz a uma espécie de tecnificação da razão. Esta postura teórica coloca Morin em perspectiva de continuidade com os trabalhos de Weber (1980), Adorno (2003; 2009), Horkheimer (1980; 2007) e Habermas (1980), os quais denunciaram os fechamentos e estrangulamentos da racionalidade moderna, manifestos, essencialmente, pelo predomínio da economia sobre as instâncias éticas, políticas e estéticas. Na leitura de Kofman (1996, p. 21), o antagonista polêmico da cruzada de Morin, ainda na década de 70, estava concentrado no determinismo estruturalista. Segundo ele, "esta ortodoxia reinante sustinha que todo o conhecimento científico está sujeito e determinado por um conjunto invariável de leis" (KOFMAN, 1996, p. 21). Até então, Morin havia seguido a trajetória de uma interpretação prometeica do marxismo hegeliano e passara, a partir de então, a realizar uma abordagem crítica da Ciência "que seria um prova contra o determinismo" (KOFMAN, 1996, p. 38).

Realizar a crítica da modernidade ou mesmo ao pensamento determinista, neste sentido é, para Morin (2002d), buscar compreender a forma como o paradigma científico moderno opera. Percurso que leva Morin a compartilhar da ideia de Habermas, enunciada em seu texto - Conhecimento e Interesse. Morin, em sua obra Ciência com Consciência (2001a), interpretou que Habermas considera que há três tipos de ciências e interesses: a) ciências empírico-formais, na qual predomina o interesse técnico de domínio da natureza; b) ciências histórico-hermenêuticas, na qual predomina o interesse prático, que visa o controle, especialmente da sociedade; c) ciência crítica, na qual predomina o interesse da emancipação humana (MORIN, 2001a, p. 47).

Logo, entende-se que, quando Morin abre o combate ao problema da simplificação, do reducionismo, do determinismo e da fragmentação da realidade, manifesto no paradigma hegemônico de ciência, está dando continuidade por outras vias à crítica da dominação e da sujeição prefaciada e anunciada pela Escola de Frankfurt. A dimensão reflexiva do conhecimento, tal como a apontada por Habermas, leva Morin a compreender a relação entre fato e valor, ou mesmo a identificar o necessário diálogo entre a ciência e a filosofia, ou mesmo entre as ciências e o mundo social. O interesse emancipatório apareceria neste aspecto de reconhecimento do caráter não neutro da ciência, ou seja, de seu caráter instrumental, marcado por interesses e usos sociais que extrapolam a própria ciência e exigem o posicionamento ético e político dos sujeitos. A própria forma de repensar a racionalidade incluiria, portanto, a necessária agência dos sujeitos em relação ao conhecimento científico, o que necessariamente aponta para a dimensão do lugar da educação.

Morin parece estar convencido que o enfrentamento da problemática social, política e educacional oriunda da modernidade não se resolve sem uma mudança radical na esfera do pensamento. $\mathrm{Na}$ interpretação de Morin, esta mudança se configura na ideia de uma "reforma do pensamento", ou seja, de novos princípios para o pensamento. Em sua obra, Para Sair do Século XX, Morin pontua que "é a política que tem mais necessidade de complexidade". Segundo ele, "ela produz ideias cada vez mais simplificadoras para as sociedades cada vez mais complexas. Produz visões cada vez mais unidimensionais para sociedades mais multidimensionais" (1986, p.154). O pressuposto assumido por Morin acerca da ideia de racionalidade o orienta a propor alternativas. Não se trata de abandonar as vias do pensamento, ou mesmo da racio- 
nalidade, mas de combater toda forma de racionalização do real. O conhecimento científico, neste sentido, não é o puro reflexo do real, mas "uma atividade construída como todos os ingredientes da atividade humana" (MORIN, 2001, p. 58). A extensão deste pensamento poderia ser atrelada à Kant (1980a; 1980b), Weber (1980), Adorno (2009), Horkheimer (1980), ou mesmo Habermas (1980), os quais evidenciaram uma relação de não correspondência entre as ideias e pensamentos ao mundo real. Em Habermas, tornou-se explícita a relação entre conhecimento e ação, ou mesmo entre conhecimento, técnica e interesse. A partir dele, podemos situar um dos elementos que ajudam a inspirar, em Edgar Morin, a necessária proposição de um paradigma da complexidade articulado com uma crítica da técnica moderna, do objetivismo científico moderno, ou da civilização técnica moderna, o que aponta para o problema de pensar o próprio pensamento.

Habermas (1980) apresenta uma preocupação do movimento intelectual crítico no século XX, o qual circunstância uma nova compreensão acerca das relações entre conhecimento, ciência, educação e sociedade. Não se trata agora de simplesmente alimentar a produção de ciência, ou mesmo de associar a ciência ao progresso indefinido da sociedade. Trata-se, outrossim, de compreender o próprio conhecimento científico e de pensar outra relação com a sociedade e a educação. Movimento que leva Morin a propor, em última instância, uma reforma do pensamento na educação, a qual considere a necessidade de um paradigma da complexidade. Os vínculos de uma reforma do pensamento sob o crivo de um paradigma da complexidade emergem, sob este pressuposto, não apenas como uma necessidade pontual de transformação da educação ou da ciência, frente a um estado de crise, mas, fundamentalmente, como uma ampla e profunda necessidade de reestruturação das próprias condições do pensamento humano nas mais distintas dimensões da vida humana em sociedade. A centralidade da questão para pensar as conexões entre o cosmos, a sociedade, o homem e a educação, assume, neste formato, um deslocamento da preocupação da transformação educativa do "plano programático" para o plano do conhecimento, ou seja, para o "plano paradigmático"; processo que abrange um questionamento do próprio "paradigma" moderno de conhecimento e a proposição de uma nova forma de pensar, na qual a comunicação, a subjetividade e a reflexividade possam ser as marcas distintivas. Essa reforma, conforme Morin, "comporta um caráter epistemológico e reflexivo" (2013, p. 184). Trata-se de entender, conforme Morin, que há várias racionalidades (racionalidade crítica, racionalidade teórica, racionalidade autocrítica e racionalidade instrumental). Segundo ele, Adorno e Horkheimer nos mostraram que a razão instrumental "está a serviço de empreendimentos nocivos, criminais ou demenciais, como o campo de concentração nazista" (MORIN, 2013, p. 185).

Esse caminho interpretativo que adotamos para ler a obra de Morin, vinculando sua produção teórica à crítica da racionalidade instrumental, nos permite compreender uma série de questões importantes que estão sendo apresentadas pelo autor para pensar no modelo imperante de ciência e de pensamento que se tornou hegemônico no contexto das modernas instituições sociais/educacionais. Esta forma de entendimento não livra Morin da crítica ou mesmo da forma como sua teoria tem sido apropriada para pensar questões históricas e políticas mais concretas. Na leitura de Vasconcelos (2002, p. 78), os estudos de Morin estão sendo apropriados "muito mais 
no campo da discussão epistemológica, da pesquisa científica e da educação do que em movimentos sociais vivos". Sua interlocução tem se dado, de forma efetiva, conforme argumenta Vasconcelos, "com o movimento feminista e ecológico, mas não com os demais movimentos centrados nas outras dimensões de opressão social, étnica/racial e discriminação" (VASCONCELOS, 2002, p. 77-79). Mas, esta crítica, conforme o próprio Vasconcelos (2002) explicita, não descredencia a empreitada geral de Morin. Sob este pressuposto, entende-se que a via interpretativa, aberta por Morin, desafia o pensamento contemporâneo para o processo de entendimento das questões educacionais vinculadas com a crise da racionalidade moderna. A hipótese sugerida por Morin, neste contexto, parece ser a de que o desafio da escola não seja apenas vinculado aos programas escolares, mas fundamentalmente ligado ao problema dos paradigmas epistêmicos que sustentam estes programas. Aspecto que, configurado a partir da tradição crítica, aponta para uma nova racionalidade no âmbito do saber-fazer escolar no sentido da emancipação humana, o que sugere, conforme o paradigma da complexidade, a emergência de uma nova relação com o conhecimento.

\section{Complexidade e educação escolar: rumo a uma nova rela- ção com o conhecimento}

"É a ausência de todo tecido social, na representação escolar da ciência, que faz dela uma ideia pobre e morta" (JAPIASSU, 1999, p. 62).

A educação escolar, em sua tarefa histórica de introduzir as novas gerações na cultura, de permitir a universalização do conhecimento, a fim de assegurar um desenvolvimento humano e uma formação que favoreça a uma crescente autonomia do espírito, incumbe-se do desafio de ensinar os aspectos mais essenciais e complexos estabelecidos em todo processo de construção do conhecimento. Ou seja, cumpre à educação escolar não apenas transmitir pacotes de conhecimentos, ou mesmo de conhecer as coisas e os conteúdos do mundo, mas ensinar uma forma de se relacionar com o conhecimento e com o mundo."Há necessidade de elaborar uma ciência nova, indispensável ao conhecimento do conhecimento: a noologia, ciência das coisas do espírito, das entidades mitológicas e dos sistemas de ideias concebidos na sua organização e no seu modo de ser específico" (MORIN, 2002f, p. 30).

Um dos aspectos centrais nesse processo deve ser o aspecto do reconhecimento do "erro e da ilusão" envolvidos em todo ato de compreensão da realidade. Esta dimensão traduz uma das preocupações do paradigma epistemológico da complexidade emergente na contemporaneidade, desafiando a educação escolar a ensinar os sujeitos a compreenderem a dinâmica implicada no processo de construção do conhecimento (MORIN, 1999). Isto possui implicações que estão para além da dinâmica meramente cognitiva, configurando-se como instâncias éticas e políticas constitutivas do conhecimento escolar, uma vez que configura a própria forma dos sujeitos lidarem com a "realidade".

De acordo com Morin (2002a), o problema do conhecimento envolve sempre a questão da interpretação da realidade. A significação dos fatos, dos acontecimentos, das situações está sempre na dependência da interpretação. "Este conhecimento, 
ao mesmo tempo tradução e reconstrução, comporta a interpretação, o que introduz o risco do erro na subjetividade do conhecedor, de sua visão de mundo e de seus princípios de conhecimento." (MORIN, 2000b, p. 20). O sujeito, ao tentar "apreender junto, o texto e o contexto", ou seja, compreender, se utiliza de sistemas de pensamento, os quais podem levar a concepções abstratas e imaginárias.

A compreensão da realidade, enquanto interpretação, percepção e tradução de um sujeito pensante, corre o risco de, ao tomar o conhecimento, a leitura da realidade, como sendo a própria realidade, cair numa situação de realismo "alucinatório" ou mesmo de racionalização. Esse não reconhecimento, segundo Morin, conduz às situações e ações mais delirantes e mutiladoras possíveis. Por isso, o problema do conhecimento, escrevera Morin, deve ser, para a educação, "um princípio e uma necessidade permanentes" (MORIN, 2000b, p. 31).

Todo conhecimento, inclusive toda percepção, é tradução e reconstrução, isto é, interpretação. Uma realidade de conjunto só se manifesta através de teorias, interpretações, sistemas de pensamento. Todo o conhecimento de uma realidade política, econômica, social, cultural depende de sistemas de interpretação da política, da economia, da sociedade, da cultura, sistemas que são interdependentes de um sistema de interpretação da história. (MORIN, 2002a, p. 125).

Por isso, para Morin, "a educação do futuro deve enfrentar o problema de dupla face do erro e da ilusão". Em sua interpretação, "o maior erro seria subestimar o problema do erro; a maior ilusão seria subestimar o problema da ilusão" (MORIN, 2000b, p. 19). O ensino dessas condições, segundo Morin, deve permitir a emergência de uma cultura que permita a compreensão da condição humana e favoreça no desenvolvimento de um pensamento livre e aberto. O novo sistema de educação, conforme advoga Morin, "ensinaria uma concepção complexificada dos termos aparentemente evidentes, não apenas de racionalidade, mas também de cientificidade, de complexidade, de modernidade, de desenvolvimento". (MORIN, 2013, p. 194).

Essa perspectiva de ensino poderia ser compreendida como estritamente epistemológica, ou seja, voltada para a apreensão de um aspecto particular de uma teoria do conhecimento, não tendo nenhuma importância cultural, científica, ética e política. A relação do homem com a realidade, com o conhecimento, ou mesmo com a verdade, poderia ser tomada como uma temática filosófica desvinculada das implicações práticas/cotidianas. Essa relação poderia, também, no plano escolar, no âmbito da constituição e organização do currículo, ao ser concebida de maneira reducionista, ser delegada exclusivamente a um único componente de ensino; como se o problema da construção do conhecimento, do pensamento e da inteligência, da consciência, fosse um problema exclusivo de uma disciplina específica.

No entanto, não é esse entendimento que o paradigma da complexidade, tematizado por Edgar Morin, quer nos permitir. O reconhecimento do problema do "erro e da ilusão" está vinculado com uma dimensão, fundamentalmente, antropológica, histórica, cultural, ética e política; por isso, perpassa todas as dimensões da vida humana, estando relacionado, de maneira muito íntima, com todas as produções e formas de ser/estar do homem no mundo. Logo, essa preocupação antropo-sócio-epis- 
temológica da relação homem/mundo/real é fundamental para a educação, no sentido que os educadores devem estar permanentemente vigilantes para os problemas dos dogmatismos, determinismos e mecanicismos que percorreram/percorrem os ditames da ciência "clássica/oficial".

Por outro lado, isso implica no reconhecimento de que as ações humanas são circunstanciadas dialogicamente pelos sistemas de pensamento e teorias empregadas para a compreensão do real. Uma visão mutilada, reducionista, descontextualizada e simplificada da realidade ocasiona uma ação mutiladora. Em outros termos, isso significa a importância do reconhecimento da relação dialógica entre pensamento e ação, entre certeza e incerteza, prosa e poesia (MORIN, 2002d), entre o imaginário e o real (MORIN, 2002e), ordem e desordem, entre verdade e falsidade. Essas dualidades são dimensões complementares, concorrentes e antagônicas de uma mesma realidade. A práxis humana, histórica, está circunscrita não só na certeza e na clareza do conhecimento e da ação, mas comporta também zonas de mistério, incerteza e ambiguidades.

O ensino dessas circunstâncias e dessas condições enquanto marcas fundamentalmente características do homem e de sua relação com o real devem permitir a emergência de uma racionalidade capaz de autocriticar-se e, por isso, de interpretar-se no seio de outras interpretações. Para Morin (1986, p. 168), "a consciência dos limites do conhecimento abre-nos o universo do conhecimento ao invés de fechá-lo". Segundo ele, "o verdadeiro conhecimento é aquele que reconhece, em seu seio, a presença da incerteza e da ignorância” (1986, p. 168).

Uma percepção complexa das condições sócio-bio-antropológicas para todo o conhecimento está relacionado com o caráter da finitude humana, da racionalidade que se reconhece enquanto histórica, e, por isso, que é capaz de reconhecer seus "limites", "incertezas" e "fragilidades" diante do real. "A verdadeira racionalidade, aberta por natureza, dialoga com o real que lhe resiste" (MORIN, 2000a, p. 23). Esta racionalidade "opera o ir e vir incessante entre a instância lógica e a instância empírica; é o fruto do debate argumentado das ideias, e não a propriedade de um sistema de ideais" (ibidem).

O caráter hermenêutico e dialógico dessa afirmação quanto à racionalidade humana estende-se para o reconhecimento de que a luta para a constituição de uma perspectiva curricular diferente para a educação escolar institucionalizada deve levar em conta não só os acertos e sucessos de uma determinada perspectiva teórica, mas também compreender os fracassos e erros envolvidos em sua aplicação. A dificuldade reside, muitas vezes, em não conseguir detectar o erro, as limitações, as ilusões envolvidas em tal empreitada.

O sucesso ou o fracasso de nossas realizações educacionais atuais precisam estar sempre circunscritas numa perspectiva histórica. Na interpretação de Morin, nossas atividades educacionais necessitam levar em conta as divisões clássicas entre ciências da natureza e ciências do espírito, entre fato e valor, razão e emoção, ética e ciência, reflexão e ação, teoria e prática (MORIN, 2003b). Esse posicionamento "contextual" pode possibilitar uma leitura dos condicionantes históricos que dificultam 
outra relação no âmbito escolar por parte dos educadores quanto à questão da complexidade do conhecimento. A tradição cultural a que estamos circunscritos "hipervaloriza" a técnica, a especialidade, considerando que, quanto mais específico for um conhecimento, mais útil e pertinente será. A tradição do conhecimento escolar atual, da forma como a entendemos, está muito vinculada a uma noção parcelar e fragmentária do conhecimento. Não porque os educadores não estudaram suficientemente em seus cursos de graduação, mas, fundamentalmente, porque esses cursos de graduação possibilitaram e validaram, muitas vezes, formações que não possibilitaram outras formas de relação com o conhecimento. A educação, numa dimensão da complexidade, "deve promover esta solidariedade em todos os campos do conhecimento e em todos os locais, principalmente dentro da escola" (PETRAGLIA, 2001, p. 138).

\section{Considerações finais}

O paradigma da complexidade, elaborado por Edgar Morin, estabelece uma relação complexa entre educação, ciência e sociedade. O pensamento de Morin evidencia, dentre outras coisas, a forma como a educação e a vida social moderna foram produzidas pelo conhecimento científico. Morin assinala, junto com outros teóricos do século XX, o princípio fundamental que marcou a modernidade no que tange a interface entre ciência, técnica e vida social, destacando para a crise da ideia de progresso e de civilização técnica. O ponto de inflexão para situar Morin nesta corrente teórica que critica a técnica (ou mesmo a racionalidade instrumental) permitiu, neste texto/estudo, situar seu pensamento numa aspiração ligada à emancipação do gênero humano de todas as formas de dominação e sujeição. Morin parece ter compreendido que o problema da dominação, como uma forma materializada em contextos sociais, culturais e políticos, se refere a formas paradigmáticas de pensar. Condição que levou o autor a problematizar a educação pelo viés do problema do conhecimento.

Este parece o caminho que permite a este pensador francês ganhar lugar no âmbito da vida educacional escolar. Concordando com outros teóricos críticos, mas detendo-se na problemática da educação escolar, Edgar Morin ousadamente propôs uma reforma do pensamento. Esta reforma implica em repensar a forma paradigmática com que o projeto social moderno cristalizou-se na educação escolar. A hiperespecialização e a excessiva compartimentalização do conhecimento, na leitura de Morin, não nos conduziu ao esplendor da civilização, mas também à barbárie. O problema do conhecimento, sob este aspecto, está ligado à ação. Os problemas da ação não se referem aos problemas práticos apenas, mas aos problemas do conhecimento. Sob este critério, Morin imagina contribuir para a desnaturalização das ideias correntes sobre conhecimento na educação. A educação escolar, conforme sustenta Morin, não apenas careceria qualificar sua lógica de distribuição do conhecimento, como fundamentalmente precisaria de uma reflexão sobre o próprio problema do conhecimento.

A emergência do paradigma da complexidade na educação escolar, sob esta preocupação, implicaria um espírito de vigilância e de compreensão acerca do conhecimento produzido. Outrossim, abriria para uma relação com o conhecimento muito mais aberta e dialogante, em que as fronteiras das áreas do conhecimento tornam-se menos rígidas e que novas áreas podem emergir. Condição que permite pensar que o 
grande desafio do pensamento é pensar e conhecer a realidade, e que esta possui uma natureza complexa, isto é, interligada (diversa e una). Para tanto, a vigilância epistemológica deveria ajudar aos professores a estarem mais atentos aos problemas do erro e da ilusão que cometem todas as formas de conhecimento, bem como as inter-retroações entre todas as formas de conhecimento.

Por último, cabe lembrar que os desafios implicados às escolas e aos educadores vinculam-se, nesta proposta, com a ideia de que a complexidade não é uma saída e uma salvação para os problemas da educação, mas, antes, um desafio para pensar a dinâmica do conhecimento. Em outros termos, isso significaria um empreendimento necessário, por parte dos educadores, para compreender a necessidade da emergência de um novo "espírito científico", "capaz de favorecer a inteligência geral, a aptidão para problematizar e realizar a ligação dos conhecimentos". De acordo com Morin,

a esse novo espírito científico, será preciso acrescentar a renovação do espírito da cultura das humanidades. Não esqueçamos que a cultura das humanidades favorece a aptidão para a abertura a todos os grandes problemas, para meditar sobre o saber e para integrá-lo à própria vida, de modo a melhor explicar, correlativamente, a própria conduta e o conhecimento de si. (MORIN, 2001, p. 33).

Decorre desta tarefa um estudo fundado na análise do pensamento e na explicitação da experiência vivida, que "deve ser empreendido desde a educação primária e deve ser prosseguido, sem interrupção, ao longo de todo ciclo pedagógico" (MORIN, 2003c, p. 246).

\section{Referências}

ADORNO, T. W. Educação e emancipação. Rio de Janeiro, Paz e Terra, 2003.

Dialética negativa. Rio de Janeiro: Jorge Zahar, 2009.

ADORNO, T. W.; HORKHEIMER, M. Dialética do esclarecimento: fragmentos filosóficos. Rio de Janeiro: Jorge Zahar, 2006.

ARENDT, H. A condição humana. Tradução de Roberto Raposo, posfácio de Celso Lafer. 10. ed., Rio de Janeiro: Forense Universitária, 2001.

HABERMAS, J. Conhecimento e interesse. São Paulo: Abril Cultural, 1980. (Os Pensadores).

HEIDEGGER, M. Ensaios e conferências. 8. ed., Petrópolis: Vozes; Bragança Paulista: Editora Universitária São Francisco, 2012.

HORKHEIMER, M. Teoria tradicional e teoria crítica. São Paulo: Abril Cultural, 1980. (Os Pensadores).

Eclipse da razão. São Paulo: Centauro Editora, 2007.

JAPIASSU, H. Um desafio à educação: repensar a pedagogia científica. São Paulo: Editora Letras \& Letras, 1999.

A crise das Ciências Humanas. São Paulo: Cortez, 2012.

KANT, I. Crítica da razão pura. São Paulo: Abril Cultural, 1980a. (Os Pensadores).

Prolegômenos. São Paulo: Abril Cultural, 1980b. (Os Pensadores). 
KOFMAN, M. Edgar Morin: do big brother à fraternidade. Lisboa: Instituto Piaget, 1996.

LEFORT, C. O Imaginário da Crise. In: NOVAES, A. A crise da razão. 2. ed., São Paulo: Companhia das Letras, 2006.

MARCONDES, D. A Crise de Paradigmas e o Surgimento da Modernidade. In: BRANDÃO, Z. A crise de paradigmas e a educação. 8. ed., São Paulo: Cortez Editora, 2002.

MARQUES, M. O. Conhecimento e modernidade em reconstrução. Ijuí: Ed. Unijuí, 1993.

MORIN, E. Para sair do séc. XX. Tradução de Vera Azambuja Harvey. Rio de Janeiro: Nova Fronteira, 1986.

O método 3: O conhecimento do conhecimento. Porto Alegre: Sulina, 1999.

Os sete saberes necessários à educação do futuro. 2. ed., São Paulo: Cortez; Brasília, DF: UNESCO, 2000b.

. Ciência com consciência. 5. ed., Rio de Janeiro: Bertrand Brasil 2001(a). 2002 a.

O método I: a natureza da natureza. Tradução IlanaHeineberg. Porto alegre: Sulina,

. Amor, poesia, sabedoria. Tradução de Edgar de Assis Carvalho. 4. ed., Rio de Janeiro: Bertrand Brasil, 2002 d.

. A religação dos saberes: o desafio do séc. XXI. Jornadas temáticas idealizadas e dirigidas por Edgar Morin. Tradução e notas, Flávia Nascimento. 3. ed., Rio de Janeiro: Bertrand Brasil, 2002e.

. O problema epistemológico da complexidade. Publicações Europa-América, $2002 \mathrm{f}$.

O método 5: a humanidade da humanidade. Tradução Juremir Machado da Silva. 2. ed., Porto Alegre: Sulina, 2003b.

. A via para o futuro da humanidade. Rio de Janeiro: Bertrand Brasil, 2013.

.X da questão: o sujeito à flor da pele. Trad. Fátima Murad. Porto Alegre: Armed, 2003c.

MORIN, E.; CIURANA, E. e MOTTA, R. D. Educar na era planetária: O pensamento complexo como método de aprendizagem pelo erro e incerteza humana. Elaborado para a UNESCO. Tradução de Sandra Trabucco Valenzuela; revisão técnica da tradução Edgar de Assis de Carvalho. São Paulo: Cortez, DF : UNESCO, 2003a.

MORIN, E; LE MOIGNE, J.A inteligência da complexidade. Tradução Nurimar Maria Falci. São Paulo: Petrópolis, 2000a.

NOVAES, A. (Org.). A crise da razão. São Paulo: Companhia das Letras; Brasília: Ministério da Cultura; Rio de Janeiro: Fundação Nacional de Arte, 2006.

PENA-VEGA, A.; ALMEIDA, E. P. O pensar complexo: Edgar Morin e a crise da modernidade. Rio de Janeiro: Garamond, 1999.

PETRAGLIA, I. Olhar sobre o olhar que olha: complexidade, holística e educação. Petrópolis: Vozes, 2001.

VASCONCELOS, E. M. Complexidade e pesquisa interdisciplinar: epistemologia e metodologia operativa. Petrópolis: Vozes, 2002.

WEBER, M. A Ética protestante e o espírito do capitalismo. São Paulo: Abril Cultural, 1980. 
Complexidade, conhecimento e educação: a emergência de um novo paradigma epistemológico no contexto contemporâneo

* Professor doutor da Universidade Regional do Noroeste do Estado do Rio Grande do Sul, Ijuí, Rio Grande do Sul, Brasil.

\section{Correspondência}

Sidinei Pithan da Silva - Universidade Regional do Noroeste do Estado do Rio Grande do Sul. Rua do Comércio, 1364, São Geraldo. CEP: 98700-000 - Ijui, Rio Grande do Sul, Brasil.

E-mail: sidinei.pithan@unijui.edu.br

Recebido em 15 de maio de 2014

Aprovado em 13 de junho de 2014 